\title{
Studying the ion transfer across liquid interface of thin organic-film-modified electrodes in the presence of glucose oxidase
}

\author{
Valentin Mirceski ${ }^{1,2} \cdot$ Biljana Mitrova $^{1} \cdot$ Vladimir Ivanovski $^{1} \cdot$ Nikolina Mitreska $^{1}$. \\ Angela Aleksovska $^{1} \cdot$ Rubin Gulaboski ${ }^{2,1}$
}

Received: 12 February 2015 /Revised: 11 April 2015 /Accepted: 16 April 2015

(C) Springer-Verlag Berlin Heidelberg 2015

\begin{abstract}
A coupled electron-ion transfer reaction at thin organic-film-modified electrodes (TFE) is studied in the presence of glucose oxidase (GOx) under voltammetric conditions. TFE consists of a graphite electrode modified with a nitrobenzene solution of decamethylferrocene (DMFC) as a redox mediator and tetrabuthylammonium perchlorate as an organic-supporting electrolyte, in contact with aqueous buffer solutions containing percholarte ions and GOx. The redox turnover of DMFC coupled with perchlorate transfer across water|nitrobenzene interface composes the coupled electronion transfer reaction. Glucose oxidase strongly adsorbs at the liquid|liquid interface affecting the coupled electron-ion transfer reaction by reducing the surface area of the liquid interface, prompting coadsorption of the transferring ion and lowering down slightly the rate of the ion transfer reaction. Although the enzyme exists as a polyvalent anion over the $\mathrm{pH}$ interval from 5.6 to 7 , it does not participate directly in the ionic current across the liquid interface and percholrate remains the main transferring ion. Raman spectroscopic data, together with the voltammetric data collected by three-phase droplet electrodes, indicate that the adsorption of the enzyme does not depend either on the redox mediator (DMFC) or the organicsupporting electrolyte, while being driven by intrinsic interactions of the enzyme with the organic solvent. The overall electrochemical mechanism is mathematically modeled by
\end{abstract}

Valentin Mirceski

valentin@pmf.ukim.mk

1 Institute of Chemistry, Faculty of Natural Sciences and Mathematics, "Ss Cyril and Methodius" University, P.O. Box 162, 1000 Skopje, Republic of Macedonia

2 Faculty of Medical Sciences, "Goce Delcev" University, P.O. Box 201, 2000 Stip, Republic of Macedonia considering linear adsorption isotherm of the transferring ion, semi-infinite mass transfer regime, and phenomenological second-order kinetic model.

Keywords Thin organic-film-modified electrodes . Liquid|liquid interface $\cdot$ Glucose oxidase $\cdot$ Ion transfer . Voltammetry

\section{Introduction}

Over the last two decades, thin organic-film-modified electrodes [1-8] (TFEs) and three-phase electrodes [9, 10] (TPEs) emerged as a simple but powerful experimental tool for studying complex coupled electron-ion transfer reactions. Their application spans over analysis of ion [11-14] or electron-transfer $[15,16]$ reactions across liquid|liquid $(\mathrm{L} \mid \mathrm{L})$ interface, study of the mechanism of redox transformation in the organic film [17-19], nanoparticle preparation [20], electrocatalysis [21], and bioelectrochemical studies of redox-inactive proteins $[22,23]$. The thin-film electrode is a rather simple system that consists of graphite electrode (GE) covered with a thin, micrometer-dimension film, of a water immiscible organic solvent $(\mathrm{O})$. The organic solvent contains a lipophilic neutral redox-active probe and a lipophilic electrolyte. By immersing the modified electrode in an aqueous electrolyte (AQ), a stable liquid|liquid interface is formed between the two liquid phases. While the potential difference at the GE|O interface is externally controlled, the potential difference at the liquid $\mathrm{O} \mid \mathrm{AQ}$ interface is mainly controlled by the partition of a common ion (e.g., $\mathrm{ClO}_{4}{ }^{-}$), present in a large excess in both liquid phases. In the course of the voltammetric experiment the electrode reaction of the redox compound is coupled with virtually simultaneous charge compensating ion transfer reaction at the other side of the liquid film, i.e., at the 
$\mathrm{O} \mid \mathrm{AQ}$ interface. In such scenario, the overall coupled electronion transfer reaction at the TFE resembles the charge transfer processes at cellular membranes, where the ion transfer reaction at one side of the membrane is energetically driven by the redox reaction at the other side of the membrane. Obviously, from a thermodynamic standpoint, TFEs are a valuable tool for mimicking some aspects of membrane processes. Accordingly, in the last decade, significant efforts have been made to study the thermodynamics [9, 11-14] and kinetics [3, 4, 24] of coupled electron-ion transfer reactions. This also includes ion transfer processes across lipid-modified L $\mid \mathrm{L}$ interface [25], as well as studies of the mechanism of redox transformations within the lipophilic membrane of biologically relevant species [17-19].

Karyakin et al. were the first who attempted to apply TFEs in the study of redox proteins. The composition of the hydrophobic (organic) phase of such an electrode consisted of a nonpolar solvent, deposited as a thin film on a strongly hydrophobic redox polymer [22, 23]. They have demonstrated that the response of TFEs could be significantly enhanced in the presence of a variety of redox-inactive proteins extracted from the aqueous phase into the organic film. Most probably, the surfactant-supported extraction of proteins actually contributed to a significant amount of the aqueous electrolyte to be present in the organic phase. The so-formed water-in-oil micro-emulsion system actually caused the enhanced electrical conductivity. This was, most probably, the critical reason for getting better features of the voltammetric response of TFEs in the presence of proteins [22] and not the protein itself.

In recent years, there has been an increased attention in the study of proteins at $\mathrm{L} \mid \mathrm{L}$ interfaces, mainly by means of the four-electrode configuration setup [26-33]. Of particular interest are electron-transfer reactions across the $\mathrm{L} \mid \mathrm{L}$ interfaces involving redox-active enzymes. Osakai et al. [34] studied an electron-transfer reaction between cytochrome $c$ in water and 1,10-dimethylferrocene in 1,2-dichloroethane. They concluded that the electrochemical mechanism is getting complicated due to the enzyme adsorption at the $\mathrm{L} \mid \mathrm{L}$ interface. The first report of an interfacial electron-transfer reaction (being catalyzed by glucose oxidase) between $\beta$-D-glucose (present in water phase) and the 1,10-dimethylferrocenium ion (present in organic phase), was done by Georganopoulou et al. [35]. The electrochemical mechanism, later analyzed theoretically by Sugihara et al. [36] by means of computer simulations, resulted in a conclusion that the oxidation of GOx mainly took place at the water side of the interface. In another work of Georganopoulou et al. [37], it has been shown that the adsorption of the enzyme at the $\mathrm{L} \mid \mathrm{L}$ interface depends on the accumulation time, enzyme concentration, and ionic strength of the aqueous phase. Using surface tension and impedance measurements, they deduced that the enzyme switches from one adsorbed state to a different one. Those two states have a different influence on the charge storage of the interfacial region. They also showed that one of the reasons for the charge storage in the interfacial layer is the possible coadsorbtion of supporting electrolyte ions.

In the present communication, an attempt was made to analyze the coupled electron-ion transfer reaction at both TFEs and TPEs under voltammetric conditions in the presence of an enzyme in the aqueous phase. Glucose oxidase (GOx), as one of the most studied enzymes [38-41], was selected due to its redox activity and high hydrophilicity. The aim of the study was to provide a methodological basis for application of TFEs to study biomacromolecules via interactions with either electron or ion transfer reaction at TFE, depending on the specific properties of the biomolecules. The other aspect of this investigation is that in spite of hundreds electrochemical studies at conventional electrodes, the electrochemical studies referring to GOx at $\mathrm{L} \mid \mathrm{L}$ interfaces are scarce [35-37].

\section{Experimental}

Decamethylferrocene (DMFC), used as a redox mediator in the organic phase, was a product of Fluka. All the other chemicals were of high purity and used as received. DMFC was dissolved in water saturated nitrobenzene (NB; $50 \mathrm{mmol} /$ $\mathrm{dm}^{3}$ ). Besides the redox compound, the thin film of nitrobenzene contained $0.1 \mathrm{~mol} / \mathrm{dm}^{3}$ tetrabuthylammonium perchlorate $\left(\mathrm{TBAClO}_{4}\right)$ salt as an electrolyte. It was important that the anion is the same as the one in the aqueous electrolyte.

A graphite rod (Black graphite, GrafTech, UCAR SNC, La Lechere France) with a diameter of $0.31 \mathrm{~cm}$ has been used as a working electrode. Before modification with the NB solution, the graphite electrode was abraded with $\mathrm{SiC}$ paper. Thereafter, approximately $0.5 \mu \mathrm{l} \mathrm{NB}$ solution was applied on the electrode surface, and the film was formed by spontaneous spreading. The TFE was then immersed into the aqueous electrolyte and used in a conventional three-electrode cell. The aqueous phase consisted of $0.1 \mathrm{~mol} / \mathrm{dm}^{3} \mathrm{LiClO}_{4}$, a phosphate or acetate buffer $\left(0.2 \mathrm{~mol} / \mathrm{dm}^{3}\right)$, and an appropriate amount of glucose oxidase. The enzyme isolated from Aspergillus niger fungus was a product of Sigma-Aldrich (CAS No: 9001-37-0). An $\mathrm{Ag} / \mathrm{AgCl}\left(3 \mathrm{~mol} / \mathrm{dm}^{3} \mathrm{KCl}\right)$ was the reference, while a Pt wire served as a counter electrode. Cyclic (CV) and square-wave voltammetry (SWV) were conducted using PalmSense potentiostat (Palm Instruments BV, Houten, The Netherlands).

Besides TFEs, in order to study the influence of different transferring ions in the presence of GOx, the three-phase droplet electrode configuration (TPE) was applied [9]. For the three-phase electrode experiments, all conditions were identical as for TFE. The difference was in the modification of the electrode and in the composition of the organic phase. Specifically, the graphite electrode was modified with a macroscopic droplet of NB solution containing only the redox mediator, and the droplet covered only the part of the electrode surface. 
After immersion into the aqueous phase, a three-phase boundary junction line was formed [9] and thus TPE too.

Raman spectra of the samples were recorded on a MicroRaman 300 from HORIBA Jobin-Yvon. The spectra were recorded employing the green Nd-Yag 532-nm laser line, while long-distance $\times 50$ lens (Olympus) was used as an objective. The maximum power on the sample without filter was $1.08 \mathrm{~mW}$. The integration time employed was $60 \mathrm{~s}$ for the Raman shift from 100 to $4000 \mathrm{~cm}^{-1}$. A diffraction grid with 1800 grooves $/ \mathrm{mm}$ was used.

\section{Results}

Under conditions of repetitive cyclic voltammetry, TFE are attributed with a well-developed and stable voltammetric response. The voltammetric response is assigned to the wellknown one-electron-one-ion electrochemical reaction, the kinetics of which is controlled by the ion transfer reaction across the $\mathrm{O} \mid \mathrm{AQ}$ interface $[3,4,24,42]$. In the presence of GOx in the aqueous phase ( $\mathrm{pH} 5.6$ ), the response gradually diminishes with potential cycling, as shown in the inset of Fig. 1. At each concentration of glucose oxidase the response stabilizes approximately after ten potential cycles at a scan rate of $v=$ $20 \mathrm{mV} / \mathrm{s}$. Comparing each 10th voltammogram recorded for different GOx concentrations, the main panel of Fig. 1 was constructed. Figure 1 shows that the decreasing of the voltammetric response is proportional to the increase in the enzyme concentration. Specifically, the current decrease obeys the following linear function: $\Delta I_{\mathrm{p}} / \mu \mathrm{A}=6.971 \log$

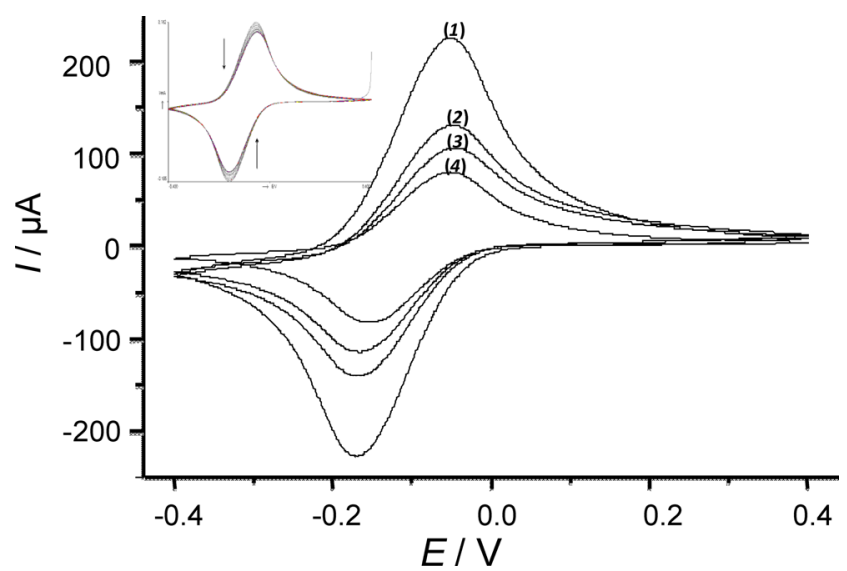

Fig. 1 The effect of the increasing concentration of GOx in the aqueous phase on the voltammetric response of TFE. The organic phase contains $50 \mathrm{mmol} / \mathrm{dm}^{3} \mathrm{DMFC}$ and $0.1 \mathrm{~mol} / \mathrm{dm}^{3} \mathrm{TBAClO}_{4}$. The aqueous phase is composed of $0.2 \mathrm{~mol} / \mathrm{dm}^{3}$ acetate buffer at $\mathrm{pH}=5.6$, containing additionally $0.1 \mathrm{~mol} / \mathrm{dm}^{3} \mathrm{LiClO}_{4}$ and $\mathrm{GOx}$ at concentration of $0 \mathrm{nmol} /$ $\mathrm{dm}^{3}$ (1), $1 \mathrm{nmol} / \mathrm{dm}^{3}(2), 10 \mathrm{nmol} / \mathrm{dm}^{3}$ (3), and $100 \mathrm{nmol} / \mathrm{dm}^{3}$ (4). The scan rate is $20 \mathrm{mV} / \mathrm{s}$. The plot shows 10 th voltammogram of the subsequent potential cycle for each GOx concentration. The inset shows the evolution of the voltammetric response with potential cycling for $10 \mathrm{nmol} / \mathrm{dm}^{3}$ GOx in the aqueous phase
$c(\mathrm{GOx}) / \mathrm{mol} \mathrm{dm}^{-3}+68.59(R=0.979)$, where $\Delta I_{\mathrm{p}}$ is the current difference recorded in the absence and the presence of corresponding concentration of the enzyme. The latter regression line spans over the concentration interval from $1 \mathrm{nmol} / \mathrm{dm}^{3}$ to $1 \mu \mathrm{mol} / \mathrm{dm}^{3}$, revealing a pronounced sensitivity of TFE to the enzyme in the aqueous phase.

Analyzing the cyclic voltammograms of Fig. 1 in more details, one finds the formal potential of the system (i.e., the mid-peak potential) slightly shifted toward more positive potentials in the presence of the enzyme. Concomitantly, the peak currents decrease, while the anodic-to-cathodic peak current ratio remains virtually unchanged. Moreover, the peak potential separation is slightly smaller in the presence of the enzyme, decreasing in proportion to the enzyme concentration.

The overall effect due to the enzyme presence depends significantly on the $\mathrm{pH}$ of the aqueous phase, potential difference across the $\mathrm{O} \mid \mathrm{AQ}$ interface, and the presence of amphiphilic species in the organic phase.

In order to inspect the role of $\mathrm{pH}$, a series of experiments analogous to that presented for $\mathrm{pH} 5.6$ (cf. Fig. 1) has been conducted but in an aqueous medium at $\mathrm{pH} 7$. Contrary to the results obtained at $\mathrm{pH} 5.6$, the response of TFE in $\mathrm{pH} 7.00$ remained completely unaffected by the enzyme concentration over a wide concentration interval $\left(10 \mathrm{nmol} / \mathrm{dm}^{3}-1 \mu \mathrm{mol} /\right.$ $\left.\mathrm{dm}^{3}\right)$. These experiments reveal that $\mathrm{pH}$ of the aqueous phase is of critical importance for the overall enzyme effect to take place (data not shown).

The influence of the potential difference across the $\mathrm{O} \mid \mathrm{AQ}$ interface has been inspected by performing a series of experiments, where the concentration of $\mathrm{ClO}_{4}^{-}$in the aqueous phase at $\mathrm{pH} 5.6$ was subjected to change. Keeping in mind that $\mathrm{ClO}_{4}^{-}$is the main potential-controlling ion at the liquid interface, these experiments were expected to reveal the effect of the potential difference across the $\mathrm{L} \mid \mathrm{L}$ interface on the overall voltammetric features. Figure 2 shows that the anodic peak current decreases with the repetitive potential cycling when the perchlorate concentration is 0.1 or $0.5 \mathrm{~mol} / \mathrm{dm}^{3}$. The concentration of the enzyme in the aqueous phase is kept constant. Note that by increasing the $\mathrm{ClO}_{4}{ }^{-}$in the aqueous phase, the inner potential at the water side of the liquid interface is progressively becoming more positive. The diminishing of the anodic peak current by potential cycling is more pronounced at higher $\mathrm{ClO}_{4}{ }^{-}$concentration, the slope of the line being 1.085 and $1.41 \mu \mathrm{A}$ for 0.1 and $0.5 \mathrm{~mol} / \mathrm{dm}^{3} \mathrm{ClO}_{4}{ }^{-}$concentration, respectively (cf. Fig. 2).

The effect of GOx is becoming insignificant in the presence of cholesterol when deliberately added to the organic phase (Fig. 3). It is well known that cholesterol is an amphiphilic compound, which accumulates effectively at the $\mathrm{O} \mid \mathrm{AQ}$ interface [43]. Under such conditions, instead of decreasing, the response is either identical or even slightly higher compared with the enzyme-free TFE [25]. Recall that cholesterol affects 


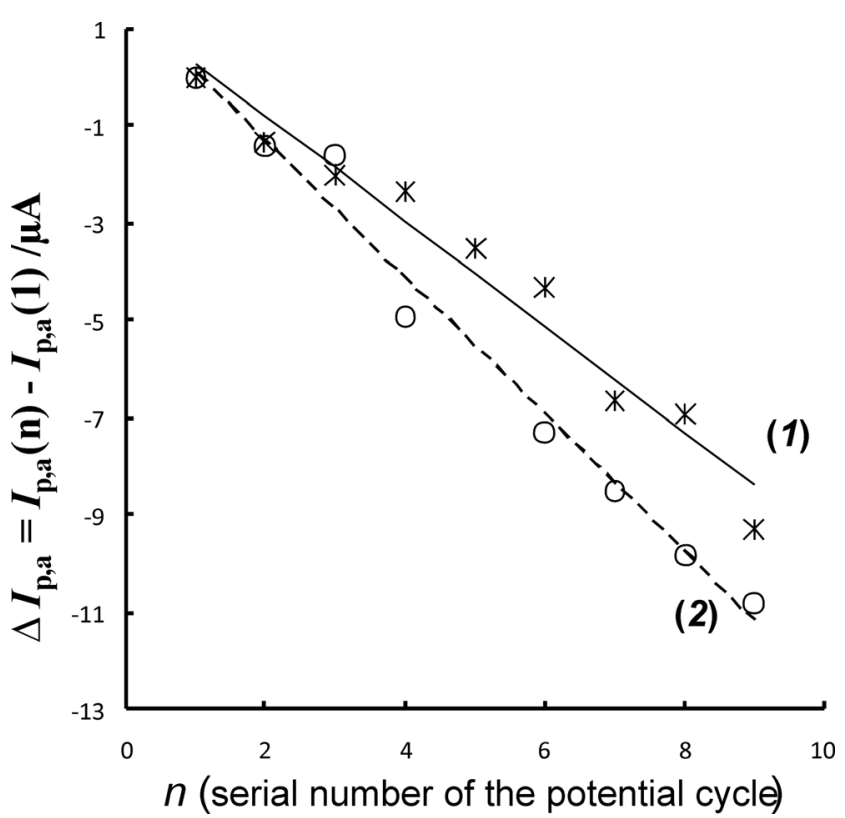

Fig. 2 The decrease of the anodic peak current of TFE by subsequent cycling of the potential for $0.1 \mathrm{~mol} / \mathrm{dm}^{3}$ (1) and $0.5 \mathrm{~mol} / \mathrm{dm}^{3}$ (2) $\mathrm{LiClO}_{4}$ in the aqueous phase in the presence of $10 \mathrm{nmol} / \mathrm{dm}^{3} \mathrm{GOx}$. On the $x$-axis, the number of the potential cycles is displayed. All other conditions are the same as for Fig. 1

significantly the physicochemical properties of both cellular membranes and $\mathrm{O} \mid \mathrm{AQ}$ interface, by compact packing of its molecules via strong hydrophobic interactions of the planar steroid ring [43].

Figure 4 summarizes an important set of experiments, the aim of which was to inspect the catalytic activity of GOxmodified TFE toward glucose oxidation. The experiments have been conducted by modification of TFE into an aqueous buffer at $\mathrm{pH} 5.6$ containing $10 \mathrm{nmol} / \mathrm{dm}^{3} \mathrm{GOx}$ with ten potential cycles at a scan rate of $v=20 \mathrm{mV} / \mathrm{s}$, until reaching a

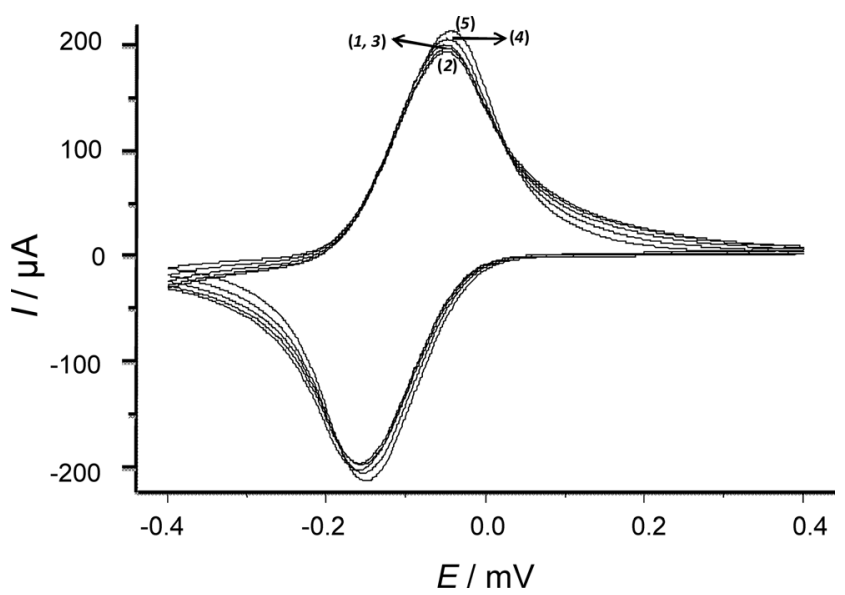

Fig. 3 The effect of the increasing concentration of GOx in the aqueous phase on the voltammetric response of TFE in the presence of $5 \mathrm{mmol} /$ $\mathrm{dm}^{3}$ cholesterol in the organic phase. The plot shows 10 th voltammogram of the subsequent potential cycling for GOx concentration of: $0 \mathrm{nmol} / \mathrm{dm}^{3}$ (1), $1 \mathrm{nmol} / \mathrm{dm}^{3}(2), 10 \mathrm{nmol} / \mathrm{dm}^{3}(3), 100 \mathrm{nmol} / \mathrm{dm}^{3}(4)$, and $1000 \mathrm{nmol} /$ $\mathrm{dm}^{3}(5)$. All other conditions are the same as for Fig. 1

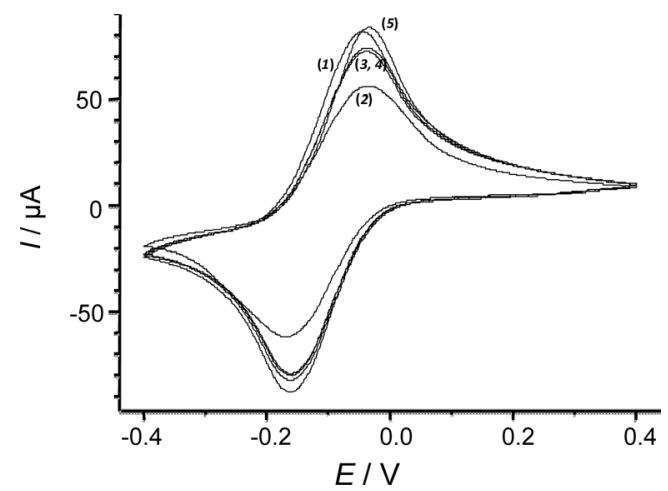

Fig. 4 The effect of glucose in the aqueous phase on the voltammetric response of TFE previously modified with GOx. Modification is conducted in an aqueous solution containing $10 \mathrm{nmol} / \mathrm{dm}^{3}$ GOx by ten potential cycles (curve 2). After modification, the electrode was transferred into an aqueous solution free of GOx, while containing different concentrations of glucose: $10 \mu \mathrm{mol} / \mathrm{dm}^{3}$ (3), $100 \mu \mathrm{mol} / \mathrm{dm}^{3}$ (4), and $1 \mathrm{mmol} / \mathrm{dm}^{3}$ (5). Curve (1) refers to the response of TFE recorded in the enzyme-free aqueous solution. All other conditions are the same as for Fig. 1

stable response (cf. the inset of Fig. 1). Following the latter incubation step, the enzyme-modified TFE was transferred into an aqueous solution free of GOx, which contained different concentration of glucose. As can be seen from Fig. 4, the voltammetric response enhances by increasing glucose concentration over the interval from $10 \mu \mathrm{mol} / \mathrm{dm}^{3}$ to $1 \mathrm{mmol} / \mathrm{dm}^{3}$ (see curves 3-5 in Fig. 4). In a set of control experiments with enzyme-free TFE, virtually no effect of glucose was observed (data not shown). Moreover, at the highest glucose concentration of $1 \mathrm{mmol} / \mathrm{l}$, the response of TFE in the enzyme-free solution slightly decreased, ruling out the direct redox communication between DMFC and glucose across the $\mathrm{O} \mid \mathrm{AQ}$ interface.

A more detailed analysis of the system has been carried out by varying the scan rate of the cyclic voltammetry, the data being summarized in Fig. 5. Figure 5a displays the variation of the cathodic and anodic peak currents as a function of the square root of the scan rate in the absence (circles) and in the presence of $10 \mathrm{nmol} / \mathrm{dm}^{3}$ GOx (triangles). While the enzyme-free system is mainly diffusion controlled, in the presence of GOx, the complexity increases significantly. The same data are re-plotted in Fig. 5b, showing the evolution of the scan rate normalized peak currents $\left(I_{\mathrm{p}} v^{-0.5}\right)$ as a function of the logarithm of the scan rate. As will be later discussed, this sort of analysis reflects the intrinsic nature of the electrode mechanism, revealing significant differences of the overall electrochemical mechanism in the presence of the enzyme. In addition, the log-log plot of the anodic peak currents versus the scan rate in the absence of the enzyme is a linear function with a slope of 0.42 , being close to the ideal value of 0.5 associated with semi-infinite diffusion controlled processes (Fig. 5c). In the presence of the enzyme, the linearity is still preserved; however, the slope of the log-log dependence 
Fig. 5 Analysis of the voltammetric response on the scan rate in the absence (circles) and the presence of $10 \mathrm{nmol} / \mathrm{dm}^{3}$ GOx (triangles) in the aqueous phase. The scan variation was conducted after ten potential cycles, i.e., after receiving a stable time-independent voltammogram. All other conditions are the same as for Fig. 1
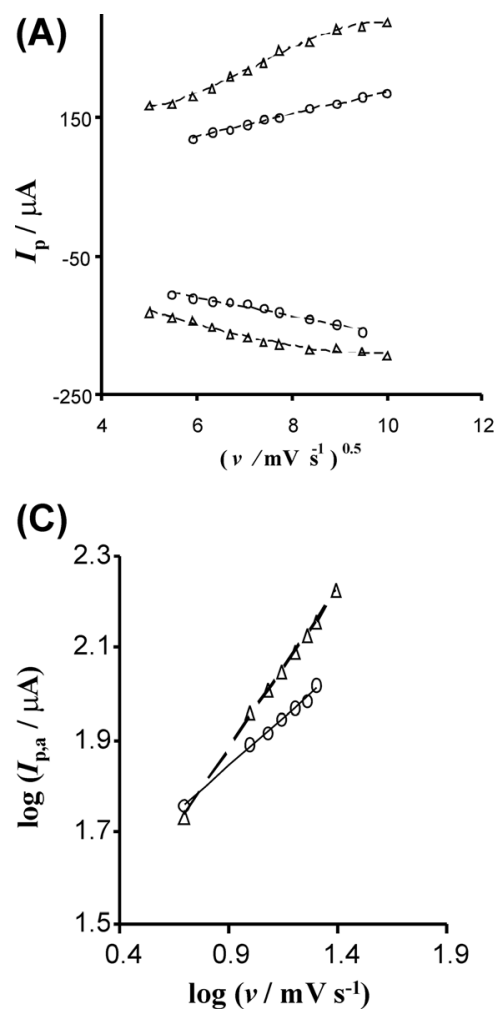

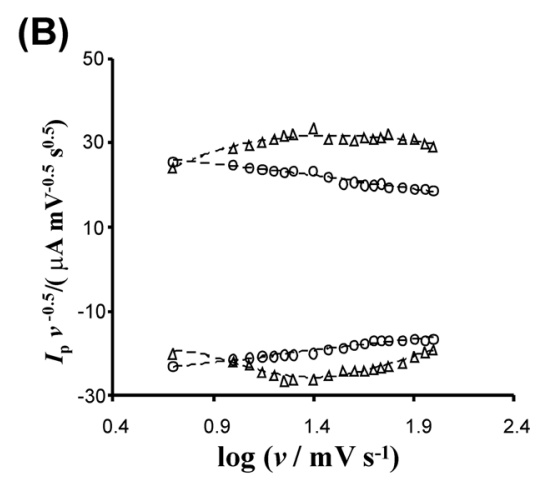

(D)

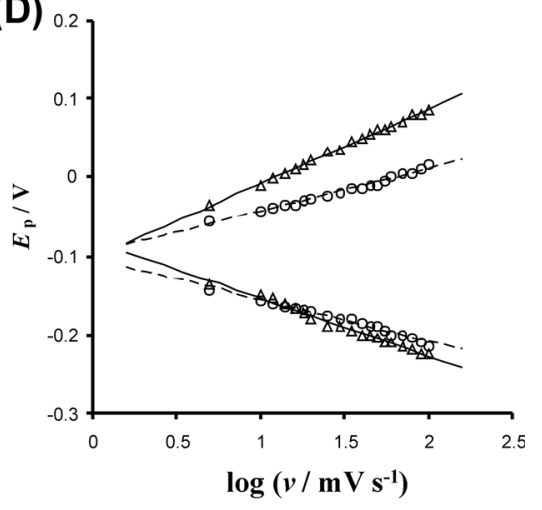

increases significantly to 0.7 , implying that the mass transfer regime is strongly affected by phenomena different than diffusion. Figure $5 \mathrm{~d}$ depicts the variation of the peak potentials with the logarithm of the scan rate. The linear shift of both cathodic and anodic peak potentials reflects the quasireversible nature of the overall electron-ion coupled electrochemical processes [3, 4, 24]. The peak potential separation increases more rapidly by increasing the scan rate in the presence of the enzyme compared with the enzyme-free electrode, implying that the overall electrochemical process is becoming slower in the presence of the enzyme.

The effective modification of TFE with GOx, i.e. the spontaneous accumulation of GOx on the $\mathrm{O} \mid \mathrm{AQ}$ interface, was additionally studied by Raman spectroscopy. For that purpose, approximately $0.2 \mu \mathrm{l}$ nitrobenzene (without DMFC and $\mathrm{TBAClO}_{4}$ ) was applied on a cleaned graphite electrode surface. The TFE was then immersed in a GOx water solution with concentration of $0.1 \mathrm{mmol} / \mathrm{dm}^{3}$. After $30 \mathrm{~s}$ incubation period, the electrode was taken out of the solution and the electrode film was subjected on air to evaporation for approximately $30 \mathrm{~min}$. After that, the dry electrode surface was recorded using micro-Raman spectroscopy. The same procedure was repeated for another two samples, where the concentration of GOx water solution was the same but with 5 and 15 min time of immersion. Figure 6a presents Raman spectra of graphite electrode, nitrobenzene, and crystal GOx. Since the scattering occurred from the surface of the electrode, where the radiation was focused, the more GOx was adsorbed, the more the spectrum of the sample represents a pure GOx spectrum (curve (c) in Fig. 6a) and less the spectrum of a graphite electrode (curve (a) in Fig. 6a). It was assumed that most of the nitrobenzene has evaporated without producing a strong signal in the sample spectrum. Figure $6 \mathrm{~b}$ presents Raman spectra of the three samples having different immersion times. It is evident that as the immersion time interval was increased, the intensity of the bands at $1596 \mathrm{~cm}^{-1}$ (the socalled $\mathrm{G}$ band) and $1325 \mathrm{~cm}^{-1}$ (D band) [44, 45] (characteristic for graphite) lowers, while the bands characteristic for crystal GOx have increased. This is particularly visible by the observation of the $\nu_{3}\left(\mathrm{CH}_{2}\right) / \nu_{3}\left(\mathrm{CH}_{3}\right)$ frequency region $3000-2800 \mathrm{~cm}^{-1}$ (cf. inset Fig. 6b), since these groups are neither present in graphite nor in nitrobenzene. Bands characteristic for nitrobenzene (which has not evaporated completely from the sample), especially the one due to the symmetric stretching $\nu_{s}\left(\mathrm{NO}_{2}\right)$ and bending $\delta_{s}\left(\mathrm{NO}_{2}\right)$ vibrations with maximum at $1345 \mathrm{~cm}^{-1}$ and $1004 \mathrm{~cm}^{-1}$, respectively [46], can still be seen in some of the sample spectra (cf. curves (e) and (f) in Fig. 6b).

Finally, to study the effect of GOx in the presence of different transferring ions, the methodology of three-phase droplet electrodes [9] has been applied. The latter electrode configuration is highly sensitive to the type of the transferring ion and is well suited for studying thermodynamics of ion transfer reactions [9-14]. In this work, the transfers of $\mathrm{SCN}^{-}, \mathrm{NO}_{3}{ }^{-}$, $\mathrm{Cl}^{-}$, and $\mathrm{Br}^{-}$ions across the $\mathrm{O} \mid \mathrm{AQ}$ interface have been studied in the presence of GOx. For this purpose, the electrode was 


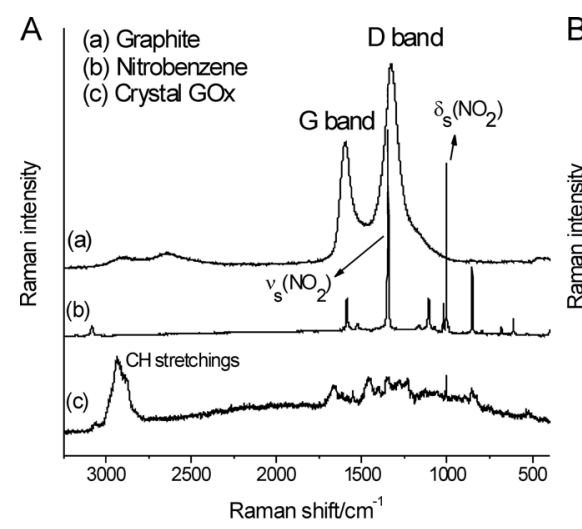

Fig. 6 a Raman spectra of graphite $(a)$, nitrobenzene $(b)$, and crystal GOx $(c)$. b Raman spectra of adsorbed GOx on graphite electrode after evaporation of nitrobenzene film for samples with different immersion times in GOx water solution: $0.5 \mathrm{~min}(d), 5 \mathrm{~min}(e)$, and $15 \mathrm{~min}(f)$. The

partly modified with the organic solution droplet containing the redox probe only. In order to increase the sensitivity and precision of the voltammetric measurements, square-wave voltammetry has been utilized [47]. The role of the enzyme was studied at $\mathrm{pH} 4.5$ and 5.6. At $\mathrm{pH} 4.5$, the enzyme is close to the isoelectric point; hence at $\mathrm{pH} 5.6$, the negative charge prevails on the enzyme surface. Typical SW voltammograms for the transfer of $\mathrm{SCN}^{-}$ions in $\mathrm{pH} 5.6$ are depicted in Fig. 7. Curve 1 corresponds to the net $\mathrm{SW}$ voltammogram recorded at the three-phase electrode in the absence of the enzyme, reflecting the transfer of $\mathrm{SCN}^{-}$from the aqueous to the organic phase. Curve 2 shows the response of the same electrode in the presence of $10 \mathrm{nmol} / \mathrm{dm}^{3}$ enzyme in the aqueous phase, the voltammogram being recorded immediately after immersing the modified electrode into the aqueous phase. Curve 3 in Fig. 7 is recorded after 5 min incubation period in the same solution. Obviously, the presence of the enzyme, as well as the

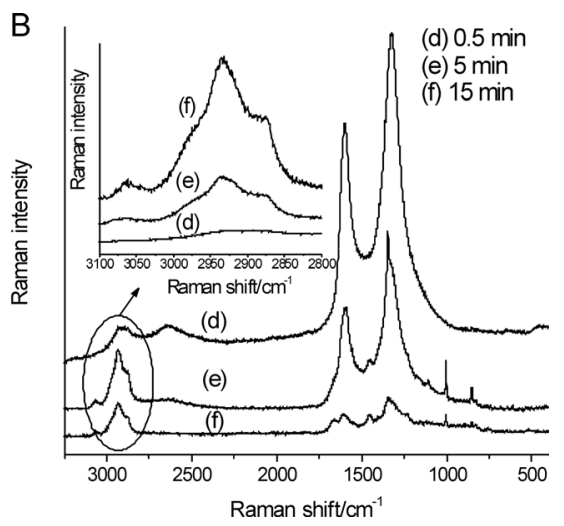

inset of (b) shows the changes in bands intensity for the frequency region of the $v_{3}\left(\mathrm{CH}_{2}\right) / v_{3}\left(\mathrm{CH}_{3}\right)$ modes (present only in GOx). These spectra were previously normalized for the band at $1596 \mathrm{~cm}^{-1} \mathrm{G}$ band

incubation period, exhibits a pronounced effect on both intensity and the position of the voltammetric peak. Commonly, voltammograms recorded in the enzyme containing aqueous solution are attributed with more positive peak potential, indication that the ion transfer process requires higher energy. The peak current is obviously increased for curve 2, recorded right after immersing the electrode into the enzyme containing aqueous phase. Prolonged incubation period is followed by blocking effects and strong diminishing of the peak height. Table 1 summarizes the peak potential shift in the presence of GOx for all studied anions. Generally, for $\mathrm{SCN}^{-}, \mathrm{NO}_{3}^{-}$, and $\mathrm{Cl}^{-}$, a positive shift of the peak potential is observed, which is more pronounced at longer incubation of the electrode. On the contrary, for $\mathrm{Br}^{-}$transfers, a shift of the net SW peak toward more negative potential was found after incubation of the electrode, indicating energetically facilitated ion transfer reaction.
Fig. 7 Typical net SW voltammograms at three-phase electrodes in: aqueous buffer at $\mathrm{pH} 5.6$ containing $0.5 \mathrm{~mol} / \mathrm{dm}^{3}$ $\mathrm{KSCN}(1)$; the aqueous phase contains additionally $10 \mathrm{nmol} /$ $\mathrm{dm}^{3}$ GOx (2); and after $5 \mathrm{~min}$ incubation of the electrode in the enzyme-containing solution (3). The parameters of the potential modulation are frequency at $8 \mathrm{~Hz}$; pulse height at $50 \mathrm{mV}$, and step potential at $1 \mathrm{mV}$. The organic phase consists of only $50 \mathrm{mmol} /$ $\mathrm{dm}^{3}$ DMFC solution in nitrobenzene

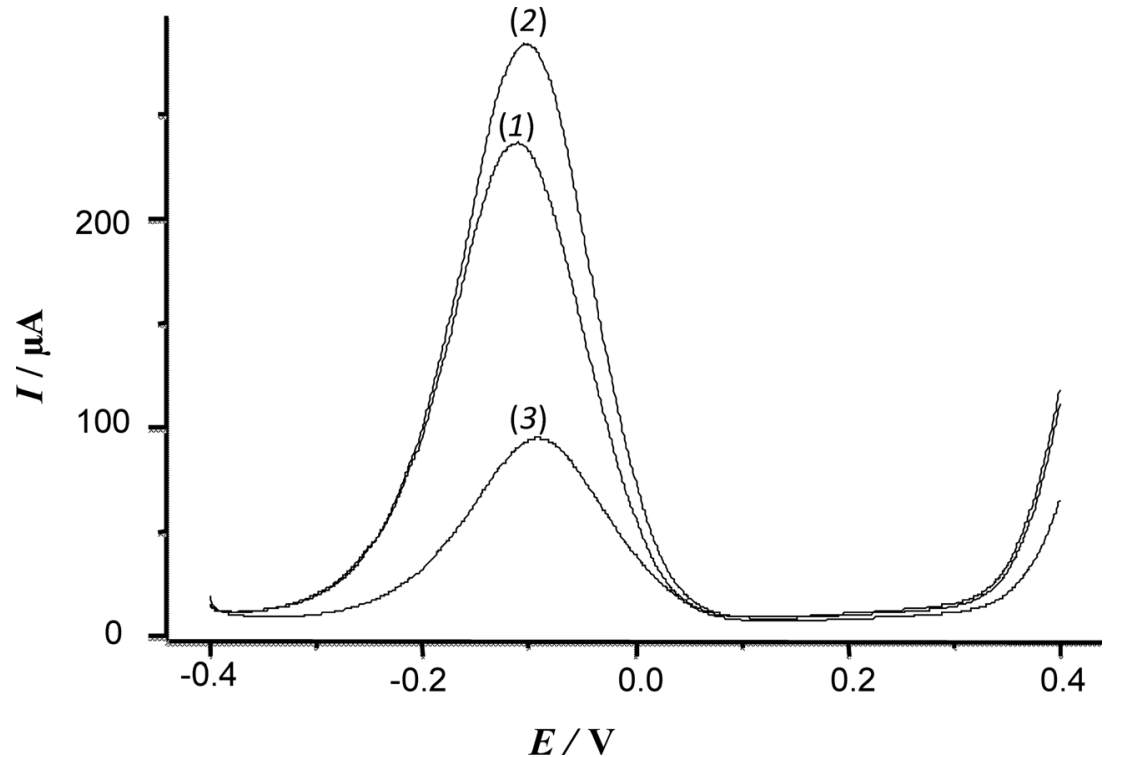


Table 1 The shift of the net SW peak potential $\left(\Delta E_{\mathrm{p}}=E_{\mathrm{p}}(\mathrm{GOx})-E_{\mathrm{p}}\right.$ (no $\mathrm{GOx})$ ) in the aqueous phase containing $10 \mathrm{nmol} \mathrm{dm}^{-3} \mathrm{GOx}$

\begin{tabular}{lllll}
\hline Transferring anion & $\mathrm{SCN}^{-}$ & $\mathrm{NO}_{3}^{-}$ & $\mathrm{Cl}^{-}$ & $\mathrm{Br}^{-}$ \\
\hline $\mathrm{pH}$ & 4.5 & & & \\
$\Delta E / \mathrm{mV}^{\mathrm{a}}$ & 10 & 30 & 3 & 6 \\
$\Delta E / \mathrm{mV}^{\mathrm{b}}$ & 19 & 55 & 50 & -11 \\
$\mathrm{pH}$ & 5.6 & & & \\
$\Delta E / \mathrm{mV}^{\mathrm{a}}$ & 8 & 42 & 78 & 7 \\
$\Delta E / \mathrm{mV}^{\mathrm{b}}$ & 19 & 55 & 50 & -11 \\
\hline
\end{tabular}

The experimental conditions are the same as for Fig. 7

${ }^{\text {a }}$ Right after immersing the three-phase droplet electrode in the enzymecontaining aqueous phase

${ }^{\mathrm{b}}$ After incubation of the electrode for $5 \mathrm{~min}$ into the enzyme- containing aqueous phase

\section{Discussion}

Electrochemical processes at thin organic-film-modified electrodes couple the electron transfer at the $\mathrm{GE} \mid \mathrm{O}$ with the ion transfer across the $\mathrm{O} \mid \mathrm{AQ}$ liquid interface. Using $\mathrm{DMFC}$ as a redox mediator dissolved in nitrobenzene, and $\mathrm{ClO}_{4}{ }^{-}$as a transferring ion, the coupled electron-ion transfer process is electrochemically quasireversible, the ion transfer being the rate controlling step [3, 4, 24, 42]. The peculiar feature of the overall system is that the $\mathrm{O} \mid \mathrm{AQ}$ liquid interface is nonpolarizable in the course of the voltammetric experiment, and its potential gradient is mainly controlled by the partition of the common $\mathrm{ClO}_{4}^{-}$ions present in both liquid phases.

In the presence of GOx in the aqueous phase (cf. Fig. 1), the formal potential of the system slightly shifts toward more positive values, while the morphology of the voltammetric response remains virtually unchanged. Hence, in spite of the fact that at $\mathrm{pH} 5.6$ the enzyme is partly negatively charged $(\mathrm{p} I=4), \mathrm{GOx}$ does not participate directly to the ion transfer reaction, while $\mathrm{ClO}_{4}{ }^{-}$remains the main transferring ion. The diminishing of the intensity of the voltammetric response by repetitive potential cycling and by increasing the concentration of the enzyme is a consequence of the accumulation of the enzyme at the liquid interface, which is in accord with other findings [35-37]. In the enzyme concentration interval from nano- to micromolar range, a stable enzyme film is formed, which, however, does not preclude the transfer of $\mathrm{ClO}_{4}{ }^{-}$ions completely, while blocking partly the surface area of the liquid interface. An important finding is that the adsorbed enzyme does not cause an increase of the resistance of the system, as could be inferred from the peak potential separation of the cyclic voltammograms presented in the main panel of Fig. 1.

The adsorption of the enzyme is mainly driven by the lipophylic interactions of the enzyme with the organic solvent [26-33, 35-37]. It is plausible to assume that the enzyme molecules are oriented at the liquid interface, with the negatively charged surface leaning toward the aqueous phase. Yet, at given $\mathrm{pH}$ (i.e., at a constant charge of the enzyme surface), the potential difference at the liquid interface affects slightly the compactness of the enzyme film, as indicated by the data in Fig. 2. The potential difference at the $\mathrm{O} \mid \mathrm{AQ}$ interface is defined as

$\Delta_{\mathrm{aq}}^{\mathrm{o}} \phi=\Delta_{\mathrm{aq}}^{\mathrm{o}} \phi_{\mathrm{ClO}_{4}^{-}}^{\theta}+\frac{R T}{F} \ln \frac{a_{\mathrm{ClO}_{4}^{-}(\mathrm{o})}}{a_{\mathrm{ClO}_{4}^{-}(\mathrm{aq})}}$,

where $\Delta_{\mathrm{aq}}^{\mathrm{o}} \phi=\phi^{\mathrm{o}}-\phi^{\mathrm{aq}}, \phi$ is the inner potential of particular phase. Hence, by increasing $c\left(\mathrm{ClO}_{4}{ }^{-}(\mathrm{aq})\right)$, the aqueous phase becomes more positive relative to the organic phase. One can assume that the repulsive interactions between oriented and negatively charged enzyme molecules decreased due to the charge compensating effect by the positive charge at the water side of the liquid interface. As a consequence, more compact enzyme film is formed at the liquid interface at higher $\mathrm{ClO}_{4}{ }^{-}(\mathrm{aq})$ concentration, providing an explanation for the experimental data in Fig. 2. However, by increasing pH from 5.6 to 7 the surface charge of the enzyme increases proportionally. As a consequence, the enzyme becomes more hydrophilic, which prevents its adsorption at the liquid interface. The latter explains why the response of TFE remains unaffected by the enzyme at $\mathrm{pH} 7$, over a wide concentration interval (from $1 \mathrm{nmol} / \mathrm{dm}^{3}$ to $1 \mu \mathrm{mol} / \mathrm{dm}^{3}$ ).

The adsorption of the enzyme at $\mathrm{pH} 5.6$ can be precluded by using an amphiphilic co-adsorbent as cholesterol, deliberately added to the organic phase (cf. Fig. 3). As an amphiphilic molecule, cholesterol is known to affect strongly the properties of cellular membranes making the membrane more fluid $[25,43]$. It also affects the properties of the $\mathrm{O} \mid \mathrm{AQ}$ interface, by accumulation and strong packing at the interface via hydrophobic interactions between the steroid moiety of its molecule and the organic phase, while the hydroxyl group is being oriented toward the aqueous phase. Obviously, the cholesterol film prevents the large enzyme molecules to penetrate though the liquid interface in the organic phase with their hydrophobic parts, which proves indirectly the tendency for adsorption of the studied enzyme at the bare $\mathrm{L} \mid \mathrm{L}$ interface. The spectroscopic data, summarized in Fig. 6, confirm independently that the studied enzyme accumulates on the $\mathrm{L} \mid \mathrm{L}$ interface. Clearly, the adsorption process is mainly driven by the lipophilic interactions of the enzyme with the organic solvent, being independent on the redox probe and the supporting electrolyte in the organic phase. The latter conclusion is additionally supported by the voltammetric experiments conducted with threephase droplet electrodes, where the adsorption of the enzyme was detected although the organic phase was free of a supporting electrolyte (cf. Fig. 7).

An important finding is that the adsorbed enzyme at the liquid interface preserves its structure and catalytic activity, as 
demonstrated through the experiments with glucose present in the aqueous phase (cf. Fig. 4), being in accord with other findings [37]. In the presence of glucose in the aqueous phase, the DMFC/DMFC ${ }^{+}$redox couple mediates the electron transfer between the electrode and the adsorbed enzyme causing an enhancement of the voltammetric response by increasing the concentration of glucose (see curves 3-5 in Fig. 4).

The scan rate analysis presented in Fig. 5 implies that the immobilized enzyme alters the overall electron-ion electrochemical mechanism at TFE. We assume that the ion transfer reaction is complicated by adsorption at the water side of the liquid interface due to specific interactions with the large enzyme molecules assembled at the interface, which is in agreement with the findings of Georganopoulou et al. [37]. Thus, the overall electrochemical reaction (Eq. 2) is additionally complicated by the adsorption equilibrium reaction of the transferring ion (Eq. 3):

$$
\begin{aligned}
& \operatorname{Red}(\mathrm{o})+\mathrm{X}^{-}(\mathrm{aq}) \rightleftarrows \mathrm{Ox}^{+}(\mathrm{o})+\mathrm{X}^{-}(\mathrm{o})+\mathrm{e}^{-} \\
& \mathrm{X}^{-}(\mathrm{aq}) \rightleftarrows \mathrm{X}^{-}(\mathrm{ads}),
\end{aligned}
$$

where $\mathrm{Red} / \mathrm{Ox}^{+}$represents the redox couple in the organic phase and $\mathrm{X}^{-}$is the transferring ion.

The mathematical modeling and simulation of the overall assumed mechanism (Eqs. 2 and 3) is presented in the next section, enabling qualitative understanding of the voltammetric properties of TFE in the presence of the enzyme. The adsorption complicated mechanism can also provide explanation of the system studied with three-phase electrodes by means of SWV (cf. Fig. 7). As will be shown below, the shift of the net SW voltmmograms toward more positive potentials in the presence of enzyme reflects the excess of the energy needed to compensate the adsorption energy of the transferring ion at the liquid interface.

\section{Theoretical consideration}

The voltammetric properties of TFE in the presence of the enzyme can be only partly rationalized with the aid of previous theories referring to the simple ion transfer reaction at TFE $[3,4,24]$. The present experimental system requires consideration of a coupled electron-ion transfer second-order electrochemical reaction (Eq. 2), additionally accompanied by adsorption of the transferring ion due to specific interactions with the immobilized enzyme (Eq. 3). To achieve this goal, we made an attempt to model the reaction mechanism by assuming the simplest linear adsorption isotherm of the transferring ion, $\beta\left(c_{\mathrm{X}(\mathrm{aq})}\right)_{x=0}=\Gamma_{\mathrm{X}(\mathrm{ads})}$. Here, $\beta(\mathrm{cm})$ is the adsorption constant, $\left(c_{\mathrm{X}(\mathrm{aq})}\right)_{x=0}$ and $\Gamma_{\mathrm{X}(\mathrm{ads})}$ are surface concentrations of the transferring ion at the water side of the liquid interface, referring to the dissolved and adsorbed state of the ion, respectively. To simplify the complexity of the system, we assume a semi-infinite mass transfer regime and kinetic model referring to a second-order electrochemical process, associated with the apparent phenomenological standard rate constant $k_{\mathrm{s} \text {,app }}\left(\mathrm{s}^{-1} \mathrm{~mol}^{-1} \mathrm{~cm}^{4}\right)$ [24]. At the beginning of the experiment, the bulk concentrations of $\operatorname{Red}(\mathrm{o}), \mathrm{X}^{-}(\mathrm{aq})$ and $\mathrm{X}^{-}(\mathrm{o})$ are $c_{\mathrm{Red}(\mathrm{o})}^{*}=0.05 \mathrm{~mol} / \mathrm{L}, c^{*}{ }_{\mathrm{X}(\mathrm{aq})}=c^{*}{ }_{\mathrm{X}(\mathrm{o})}=0.1 \mathrm{~mol} / \mathrm{dm}^{3}$, respectively, while $\mathrm{c}^{*}{ }_{\mathrm{Ox}(\mathrm{o})}=0$ as the experiment starts with no bulk concentration of Ox species (cf. Fig. 1). Mathematical solutions for the surface concentrations of $\operatorname{Red}(0), \mathrm{Ox}(\mathrm{o})$, and $\mathrm{X}^{-}(\mathrm{o})$ are [48]:

$c(i)_{x=0}=c_{i}^{*}+k \int_{0}^{t} \frac{I(\tau)}{F A \sqrt{D}} \frac{\mathrm{d} \tau}{\sqrt{\pi(t-\tau)}}$

where $c_{i}^{*}$ is the bulk concentration of particular species and $k=-1$ for $\operatorname{Red}(\mathrm{o})$, and $k=1$ for both $\operatorname{Ox}(\mathrm{o})$ and $\mathrm{X}^{-}(\mathrm{o})$ species. The solution for the surface concentration of the adsorbing ion at the liquid interface is:

$$
\begin{gathered}
\left(c_{\mathrm{X}(\mathrm{aqq})}\right)_{x=0}=c_{\mathrm{X}(\mathrm{aq})}^{*}\left[1-\exp \left(\xi^{2} t\right) \operatorname{erfc}(\xi \sqrt{t})\right]-\xi \int_{0}^{t} \frac{I(\tau)}{F A \sqrt{D}} \exp \left[\xi^{2}(t-\tau)\right] \\
\operatorname{erfc}(\xi \sqrt{t-\tau}) \mathrm{d} \tau
\end{gathered}
$$

where $\xi=\frac{\sqrt{D}}{\beta}$ [48]. In the absence of adsorption, the solution for $\mathrm{X}^{-}(\mathrm{aq})$ is given by Eq. (4), taking into account its bulk concentration and $k=-1$. In Eqs. (4) and (5), $I$ is the current, $A$ is the electrode surface area, or the surface area of the liquid interface, $t$ is time, $F$ is Faraday constant, and $D$ is the diffusion coefficient, being set to the same value for all electroactive species. The solution for the surface concentration of electroactive species are combined with the secondorder kinetic equation:

$\frac{I}{F A}=k_{\mathrm{s}, \mathrm{app}} \exp (\alpha \phi)\left[\left(c_{\mathrm{Red}(\mathrm{o})}\right)_{x=0}\left(c_{\mathrm{X}(\mathrm{aq})}\right)_{x=0}-\exp (-\phi)\left(c_{\mathrm{OX}(\mathrm{o})}\right)_{x=0}\left(c_{\mathrm{X}(\mathrm{o})}\right)_{x=0}\right]$

where $\alpha$ is the transfer coefficient and $\phi$ is the dimensionless potential $\phi=\frac{F}{R T}\left(E-E^{0^{\prime}}\right)$, defined as a difference of the electrode potential $E$ and the formal potential $E^{\circ}$, of the reaction (2) [24]. For numerical simulation, the step-function method was applied adopted for cyclic voltammetry [49]. For this purpose, the time increment was defined as $d=\frac{\Delta E R T}{50 v F}$, where $\Delta E$ is the potential step, $R$ is universal gas constant, $T$ is temperature, and $v$ is the scan rate.

The outcomes of the simulations, conducted with the software package Mathcad, are represented in the following form: $I=F A c_{\mathrm{X}_{(\mathrm{aq})}} \sqrt{D v F / R T} \Psi$, where $\Psi$ is the dimensionless current function, calculated by simulations, which represents the 
intrinsic voltammetric properties of the electrochemical mechanism.

Simulations reveal that voltammetric properties are mainly controlled by adsorption parameter $\rho=\frac{\sqrt{D}}{\beta \sqrt{v F / R T}}$, kinetic parameter $\kappa=\frac{k_{\text {sapp }} c_{(\text {Xaq) }}}{\sqrt{D v F / R T}}$ and concentration ratios $C_{1}=\frac{c_{\mathrm{Red}(\mathrm{o})}^{-}}{c_{\mathrm{X}(\mathrm{aq})}}$ and $C_{2}=\frac{c_{\overrightarrow{\mathrm{X}(0)}}}{c_{\mathrm{X}(\mathrm{a} a)}}$. When the adsorption is very week $(\beta \rightarrow 0)$, the outcome of the simulation for the adsorption mechanism (Eqs. 2 and 3 ) is identical with the adsorption free mechanism simulation (Eq. 2 only), as shown in Fig. 8a. The later simple comparison supports the correctness of the complex model considering the adsorption of the transferring ion. In addition, Fig. $8 \mathrm{~b}$ shows the effect of the adsorption constant of the transferring ion on the simulated cyclic voltammograms. Increasing the strength of adsorption, the mid-peak potential shifts toward more positive values in proportion to the adsorption energy of the transferring ion. This sort of theoretical
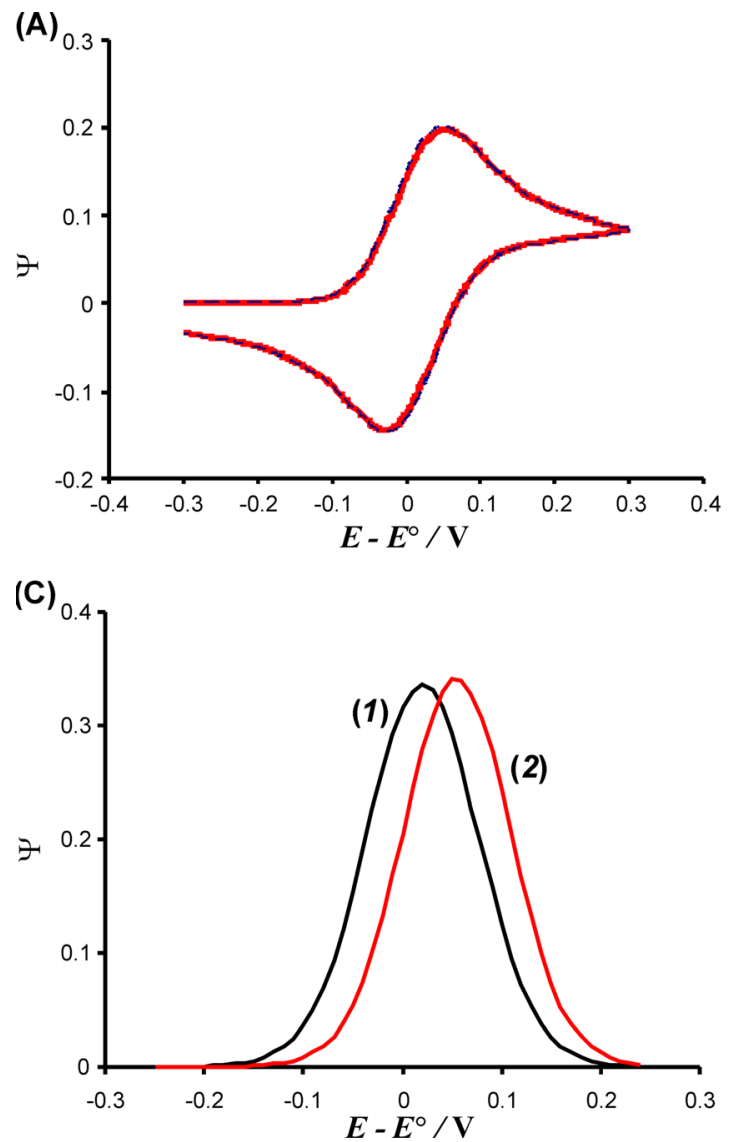

Fig. 8 Theoretical data. a Comparison of the simulated data for the model with no adsorption (red line) and the model with adsorption for low adsorption constant of $\beta=10^{-3} \mathrm{~cm}$ (blue dotted line). b The effect of the adsorption constant for cyclic voltammetry. The values of the adsorption are: $\beta=0 \mathrm{~cm}(1), 0.01 \mathrm{~cm}(2), 0.02 \mathrm{~cm} \mathrm{(3),} \mathrm{and} 0.1 \mathrm{~cm}$ (4). c The effect of the adsorption constant for square-wave voltammetry. The values of the adsorption are $\beta=0 \mathrm{~cm}(1)$ and $0.01 \mathrm{~cm}$ (2). d The fitting of the experimental (triangles) with the theoretical (circles) data for the peak potential separation of cyclic voltammograms for different scan rate. The analysis explains the slight shift of the mid-peak potential of voltammograms presented in the main panel of Fig. 1 by increasing the concentration of the adsorbed enzyme, which prompts coadsorption of the transferring $\mathrm{ClO}_{4}{ }^{-}$ions. Note that the strength of the adsorption does not affect the peak current in simulated voltammograms (cf. Fig. 8b), as the transferring ion is not the mass transfer limiting species in the overall second-order reaction (2) (i.e., $c_{\mathrm{X}(\mathrm{aq})}^{*}>c_{\mathrm{Red}(\mathrm{o})}^{*}$ ). In the real voltammograms (cf. Fig. 1), as previously mentioned, the decreasing of the current is primarily due to decreasing of the surface area of the liquid interface by adsorption of the enzyme.

While the presence of adsorption generally shifts the formal potential toward higher values, the increasing of the surface concentration of the adsorbed ion $\Gamma_{\mathrm{X}(\mathrm{ads})}$ by applying an accumulation period prior to the potential scan has an opposite effect. This was confirmed by simulations conducted by applying an extended accumulation period prior to the application of the potential modulation. This peculiarity is a

(B)

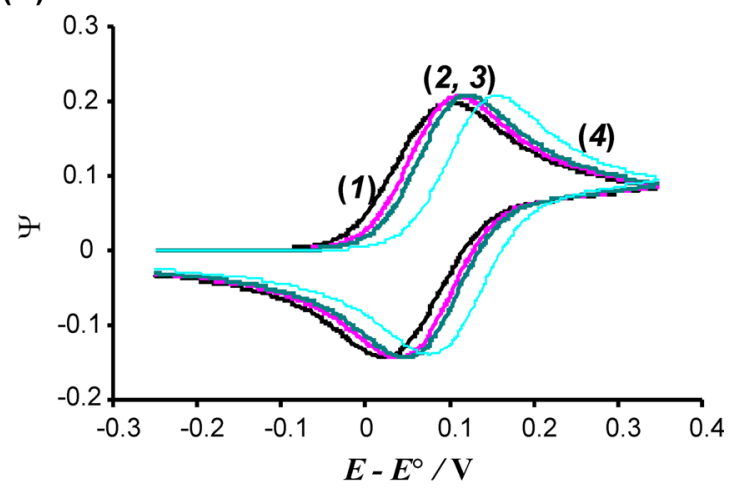

(D)

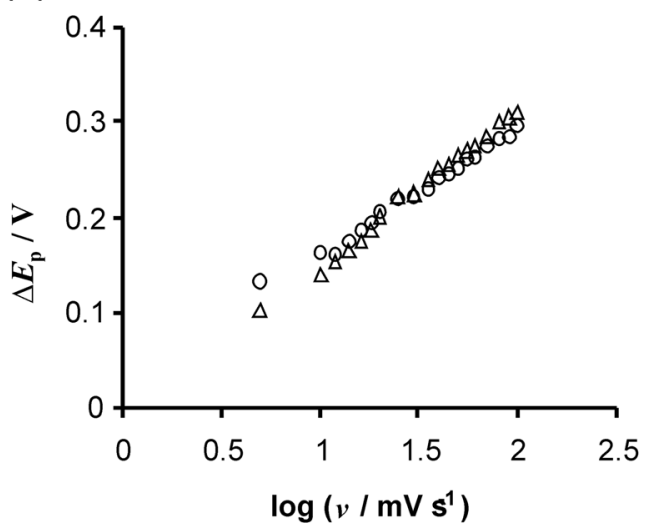

experimental conditions are the same as for Fig. $5 \mathrm{~d}$. The theoretical data are calculated for $k_{\mathrm{s} \text {, app }}=10 \mathrm{~cm}^{4} \mathrm{~s}^{-1} \mathrm{~mol}^{-1}, \beta=0.1 \mathrm{~cm}$, and accumulation time of $100 \mathrm{~s}$. The rate constant for (a)-(c) is $k_{\mathrm{s}, \text { app }}=50 \mathrm{~cm}^{4} \mathrm{~mol}^{-1} \mathrm{~s}^{-1}$. The other conditions of the simulations valid for all panels are $D=1 \times$ $10^{-6} \mathrm{~cm}^{2} \mathrm{~s}^{-1}, \alpha=0.5, c_{\text {Red }(0)}^{*}=0.05 \mathrm{~mol} / \mathrm{dm}^{3}, c_{\mathrm{X}(\mathrm{aq})}^{*}=c_{\mathrm{X}(\mathrm{o})}^{*}=0.1 \mathrm{~mol} / \mathrm{dm}^{3}$, and $c_{\mathrm{Ox}}^{*}=0$. For $\mathrm{CV}$ simulations $v=5 \mathrm{mV} / \mathrm{s}$ and for SWV frequency $f=$ $10 \mathrm{~Hz}$, height of the pulses ( $\mathrm{SW}$ amplitude) $E_{\mathrm{sw}}=50 \mathrm{mV}$, and step potential $\Delta E=10 \mathrm{mV}$ 
consequence of the second-order nature of the overall electrochemical process (Eq. 2) [50]. An increased surface concentration of the transferring ion at the $\mathrm{L} \mid \mathrm{L}$ interface shifts the equilibrium reaction (2) toward the right-hand side, which is manifested as a shift of the anodic peak toward less positive potentials by increasing the accumulation time. Due to these reasons, for a given value of the scan rate, the peak potential separation is slightly deceased in the presence of enzyme, the decreasing being proportional to the enzyme concentration as shown in Fig. 1 and discussed in "Results."

Figure $8 \mathrm{c}$ shows the effect of the adsorption on the simulated net SW voltammograms. In accord with the data obtained by cyclic voltammetry, the net SW peak shifts toward more positive potentials in the presence of adsorption, which explains the experimental results obtained with SWV and three-phase electrodes (cf. Fig. 7).

In the absence of adsorption, simulations predict that the anodic and cathodic peak currents in cyclic voltammetry would be linear functions of $v^{1 / 2}$. Thus, the $\log (I)$ vs. $\log (v)$ plot is a linear function with a slope 0.5 , as a result of the semi-infinite mass transfer regime. This explains the experimental data presented in Fig. 5a, c (circles), corresponding to the experiments conducted in the absence of the enzyme. Considering the definition of the real current as $I=F A c_{\mathrm{X}(\mathrm{aq})} \sqrt{D v F / R T} \Psi$, it follows that the ratio $\frac{I}{\sqrt{v}}$ is equivalent to the dimensionless function $\Psi$. This explains the results presented in Fig. 5b. In the case when the adsorption of the transferring ion is taking place, the dimensionless function $\Psi$ depends on both $\rho$ and $\kappa$. Thus, the variation of the scan rate affects simultaneously both parameters, resulting in a very complex nonlinear variation of the function $\Psi$. This result now explains the complex nonlinear variation of the ratio $\frac{I}{\sqrt{v}}$ vs. $\log (v)$ presented in Fig. 5b (triangles) measured in the presence of adsorbed enzyme.

In the absence of adsorption, simulations reveal that the dimensionless function $\Psi$ decreases with $\log (v)$, due to the quasireversible nature of the overall electrochemical process. The influence of the scan rate is manifested through the kinetic parameter $\kappa$ only, which decreases by increasing $v$. Thus, in agreement with the simulations data, the ratio $\frac{I}{\sqrt{v}}$ decreases monotonically with $\log (v)$ for experiments in the absence of the enzyme (cf. Fig. 5b, circles).

The peak potential separation increases with $\log (v)$ due to the quasireversible nature of the electrochemical process, regardless of the enzyme presence (cf. Fig. 5d). The peak potential separation increase with scan rate more rapidly in the presence of the enzyme, indicating that rate of ion transfer is slower compared with the bare $\mathrm{L} \mid \mathrm{L}$ interface. The best fitting result of the experimental and theoretical data for the experiments in the presence of enzyme is given in Fig. 8d, corresponding to the apparent rate constant for the ion transfer process of $k_{\mathrm{s}, \text { app }}=10 \mathrm{~cm}^{4} \mathrm{~s}^{-1} \mathrm{~mol}^{-1}$ (linear regression correlation coefficient $R^{2}=0.994$ ), while the experiments in the absence of enzyme are attributed with the rate constant of $k_{\mathrm{s}, \mathrm{app}}=$
$15 \mathrm{~cm}^{4} \mathrm{~s}^{-1} \mathrm{~mol}^{-1}$ (data not shown). Obviously, due to the specific interactions of the transferring ion with the immobilized enzyme, the rate of the ion transfer reaction is lowered compared with the bare $\mathrm{L} \mid \mathrm{L}$ interface.

\section{Conclusions}

It has been demonstrated that thin organic-film-modified electrodes in combination with voltammetric techniques are well suited and highly sensitive tool for studying enzymes at liquid|liquid interfaces. Glucose oxidase adsorbs strongly at the water|nitrobenzene interface affecting significantly the ion transfer across the interface, even at nanomolar concentration level of the enzyme. The effective accumulation of the enzyme at the liquid interface could be monitored in situ by repetitive cyclic voltammetry. The surface enzyme concentration at the liquid interface depends on the enzyme concentration, accumulation time, $\mathrm{pH}$, and concentration of the aqueous electrolyte. Under presented experimental conditions of $\mathrm{pH}$ and electrolyte concentration, a stable enzyme film retaining its enzymatic activity is formed at the liquid interface. The active enzyme enables electron transfer between the redox mediator in the organic phase and glucose in the aqueous phase. The compactness of the enzyme film increases by increasing the concentration of the transferring perchlorate ions in the aqueous phase. This is explained by electrostatic shielding effect and decreasing of the repulsive interactions between adsorbed enzyme molecules, which supports findings of other authors [37]. Spectroscopic Raman data, together with the voltammetric data collected with three-phase droplet electrodes, imply that the enzyme adsorption does not depend on the redox mediator or the supporting electrolyte in the organic phase Adsorbtion is driven by intrinsic interactions of the enzyme with the organic solvent. The adsorption of the enzyme prompts coadsorption of the transferring ion, thus altering the overall mechanism of the coupled electron-ion transfer reaction at TFEs. The modeling of the electrochemical mechanism on the basis of phenomenological second-order kinetic model provides a basis for in-depth understanding of the voltammetric properties of the system. A comparison of the theoretical and experimental data collected by varying the scan rate in cyclic voltammetry indicates that besides coadsorption, the presence of enzyme slightly slows down the transfer of perclorates across the water|nitrobenzene interface.

Acknowledgments VM and RG acknowledge Alexander von Humboldt foundation for the financial support from the Research Group Linkage Programme 3.4-Fokoop-DEU/1128670, as well as the support of DAAD foundation through multilateral project "International Masters and Postgraduate Programme in Materials Science and Catalysis" (MatCatNet). VM also acknowledges with gratitude the support through the COST Action CM1302. 


\section{References}

1. Shi C, Anson CF (1998) A simple method for examining the electrochemistry of metalloporphyrins and other hydrophobic reactants in thin layers of organic solvents interposed between graphite electrodes and aqueous solutions. Anal Chem 70:3114-3118

2. Shi C, Anson CF (1998) Simple electrochemical procedure for measuring the rates of electron transfer across liquid/liquid interfaces formed by coating graphite electrodes with thin layers of nitrobenzene. J Phys Chem B 102:9850-9854

3. Deng H, Huang X, Wang L, Tang A (2009) Estimation of the kinetics of anion transfer across the liquid/liquid interface, by means of Fourier transformed square-wave voltammetry. Electrochem Commun 11:1333-1336

4. Deng H, Huang X, Wang L (2010) A simultaneous study of kinetics and thermodynamics of anion transfer across the liquid/liquid interface by means of Fourier transformed large-amplitude square-wave voltammetry at three-phase electrode. Langmuir 26:19209-19216

5. Molina A, Ortuno AJ, Serena C, Torralba E, Gonzales J (2010) Advances in the study of ion transfer at liquid membranes with two polarized interfaces by square wave voltammetry. Electroanalysis 22:1634-1642

6. Ortuno AJ, Serna C, Molina A, Torralba E (2009) Ion transfer square wave voltammetry of ionic liquid cations with a solvent polymeric membrane ion sensor. Electroanalysis 21:2297-2302

7. Zhou M, Gan S, Zhong L, Su B, Niu L (2010) Ion transfer voltammetry by a simple two polarized interfaces setup. Anal Chem 82 : 7857-7860

8. Quentel F, Mirceski V, L'Her M, Stankoska K (2012) Assisted ion transfer at organic film-modified electrodes. J Phys Chem C 116: 22885-22892

9. Scholz F, Schröder U, Gulaboski R (2005) Electrochemistry of immobilized particles and droplets. Springer, Heidelberg

10. Vagin YM, Karyakin AA, Vuorema A, Sillanpaa M, Meadows H, Del Campo FJ, Cortina-Puig M, Bulman Page CP, Chan Y, Marken F (2010) Coupled triple phase boundary processes: liquid-liquid generator-collector electrodes. Electrochem Commun 12:455-458

11. Scholz F, Komorsky-Lovric S, Lovric M (2000) A new access to Gibbs energies of transfer of ions across liquid|liquid interfaces and a new method to study electrochemical processes at well-defined three-phase junctions. Electrochem Commun 2:112-118

12. Scholz F, Gulaboski R (2005) Gibbs energies of transfer of chiral anions across the interfacewater|chiral organic solvent determined with the help of three-phase electrodes. Faraday Discuss 129:169-177

13. Bak E, Donten M, Stojek Z, Scholz F (2007) The punctured droplet electrode - a new three-phase electrode with well defined geometry. Electrochem Commun 9:386-392

14. Quentel F, Mirceski V, L'Her M (2008) Electrochemical study of the thermodynamics and kinetics of hydrophilic ion transfers across water|n-octanol interface. J Solid State Electrochem 12:31-39

15. Mirceski V, Quentel F, L'Her M, Elleouet C (2007) Homogeneous versus heterogeneous catalysis at electrodes modified with a thin organic layer: theoretical and experimental study under conditions of square-wave voltammetry. J Phys Chem C 111:8283-8290

16. Barker A, Unwin PR (2000) Assessment of a recent thin-layer method for measuring the rates of electron transfer across liquid/ liquid interfaces. J Phys Chem B 104:2330-2340

17. Mirceski V, Gulaboski R, Bogeski I, Hoth M (2007) Redox chemistry of Ca-transporter 2-palmitoylhydroquinone in an artificial thin organic film membrane. J Phys Chem C 111:6068-6076

18. Bogeski I, Gulaboski R, Kappl R, Mirceski V, Stefova M, Petreska J, Hoth M (2011) Calcium binding and transport by coenzyme Q. J Am Chem Soc 133:9293-9303
19. Munoz AAR, Banks EC, Davies JT, Angnes L, Compton GR (2006) The electrochemistry of tetraphenyl porphyrin iron(III) within immobilized droplets supported on platinum electrodes. Electroanalysis 18:649-654

20. Mirceski V, Gulaboski R (2006) Simple electrochemical method for deposition and voltammetric inspection of silver particles at the liquid-liquid interface of a thin-film electrode. J Phys Chem B 110:2812-2820

21. Mirceski V, Aleksovska A, Pejova B, Ivanovski V, Mitrova B, Mitreska N, Gulaboski R (2014) Thiol anchoring and catalysis of gold nanoparticles at the liquid interface of thin-organic film-modified electrodes. Electrochem Commun 39:5-8

22. Vagin YM, Trashin AS, Ozkan ZS, Karpachova PG, Karyakin AA (2005) Electroactivity of redox-inactive proteins at liquid|liquid interface. J Electroanal Chem 584:110-116

23. Vagin YM, Trashin AS, Karpachova PG, Klyachko LN, Karyakin AA (2008) Protein extracting electrodes: insights in the mechanism. J Electroanal Chem 623:68-74

24. Quentel F, Mirceski V, L'Her M (2005) Kinetics of anion transfer across the liquid|liquid interface of a thin organic film modified electrode, studied by means of square-wave voltammetry. Anal Chem 77:1940-1949

25. Quentel F, Mirceski V, L'Her M, Spasovski F, Gacina M (2007) Electrochemical study of hydrophilic ion transfers across cholesterol modified water-nitrobenzene interface by means of thin film electrodes. Electrochem Commun 9:2489-2495

26. Vagin YM, Malyh VE, Larionova IN, Karyakin AA (2003) Spontaneous and facilitated micelles formation at liquid/liquid interface: towards amperometric detection of redox inactive proteins. Electrochem Commun 5:329-333

27. Herzog G, Kam V, Arrigan WMD (2008) Electrochemical behaviour of haemoglobin at the liquid/liquid interface. Electrochim Acta 53:7204-7209

28. Kivlehan F, Lanyon HY, Arrigan WMD (2008) Electrochemical study of insulin at the polarized liquid-liquid interface. Langmuir 24:9876-9882

29. Herzog G, Moujahid W, Strutwolf J, Arrigan WMD (2009) Interactions of proteins with small ionised molecules: electrochemical adsorption and facilitated ion transfer voltammetry of haemoglobin at the liquid|liquid interface. Analyst 134:1608-1613

30. Scanlon DM, Jennings E, Arrigan WMD (2009) Electrochemical behaviour of hen-egg-white lysozyme at the polarised water/1,2dichloroethane interface. Phys Chem Chem Phys 11:2272-2280

31. Scanlon DM, Strutwolf J, Arrigan WMD (2010) Voltammetric behaviour of biological macromolecules at arrays of aqueous|organogel micro-interfaces. Phys Chem Chem Phys 12: 10040-10047

32. Alvarez de Eulate E, Arrigan WMD (2012) Adsorptive stripping voltammetry of hen-egg-white-lysozyme via adsorption-desorption at an array of liquid-liquid microinterfaces. Anal Chem 84: 2505-2511

33. Collins JC, Lyons C, Strutwolf J, Arrigan WMD (2010) Serumprotein effects on the detection of the $\beta$-blocker propranolol by ion-transfer voltammetry at a micro-ITIES array. Talanta 80 : 1993-1998

34. Imai Y, Sugihara T, Osakai T (2012) Electron transfer mechanism of cytochrome $c$ at the oil/water interface as a biomembrane model. J Phys Chem B 116:585-592

35. Georganopoulou DG, Caruana DJ, Strutwolf J, Williams DE (2000) Electron transfer mediated by glucose oxidase at the liquid/liquid interface. Faraday Discuss 116:109-118

36. Sugihara T, Hotta H, Osakai T (2004) Electrochemical control of glucose oxidase-catalyzed redox reaction using an oil/water interface. Phys Chem Chem Phys 6:3563-3568 
37. Georganopoulou GD, Williams ED, Pereira MC, Silva F, Su TJ, Lu RJ (2003) Adsorption of glucose oxidase at organic-aqueous and air-aqueous interfaces. Langmuir 19:4977-4984

38. Palanisamy S, Vilian ETA, Chen S (2012) Direct electrochemistry of glucose oxidase at reduced graphene oxide/zinc oxide composite modified electrode for glucose sensor. Int J Electrochem Sci 7: 2153-2163

39. Norouzi P, Faridbod F, Larijani B, Ganjali RM (2010) Glucose biosensor based on MWCNTS-gold nanoparticles in a nafion film on the glassy carbon electrode using flow injection FFT continuous cyclic voltammetry. Int J Electrochem Sci 5:1213-1224

40. Yokoyama K, Kayanuma Y (1998) Cyclic voltammetric simulation for electrochemically mediated enzyme reaction and determination of enzyme kinetic constants. Anal Chem 70:3368-3376

41. Ragupathy D, Gopalan IA, Lee K (2009) Synergistic contributions of multiwall carbon nanotubes and gold nanoparticles in a chitosanionic liquid matrix towards improved performance for a glucose sensor. Electrochem Commun 11:397-401

42. Gulaboski R, Mirceski V, Pereira MC, Cordeiro SDN, Silva AF, Quentel F, L'Her M, Lovric M (2006) A comparative study of the anion transfer kinetics across a water/nitrobenzene interface by means of electrochemical impedance spectroscopy and squarewave voltammetry at thin organic film-modified electrodes. Langmuir 22:3404-3412

43. Kim K, Kim C, Byun Y (2001) Preparation of a dipalmitoylphosphatidylcholine/cholesterol Langmuir-Blodgett monolayer that suppresses protein adsorption. Langmuir 17: 5066-5070

44. Hauptman N, Vesel A, Ivanovski V, Klanjšek GM (2012) Electrical conductivity of carbon black pigments. Dyes Pigments 95:1-7

45. Bokobza L, Bruneel JL, Couzi M (2014) Raman spectroscopy as a tool for the analysis of carbon-based materials (highly oriented pyrolitic graphite, multilayer grapheme and multiwall carbon nanotubes) and of some of their elastomeric composites. Vib Spectrosc 74:57-63

46. Green JHS, Kynaston W, Lindsey AS (1961) The vibrational spectra of benzene derivatives - I: nitrobenzene, the benzoate ion, alkali metal benzoates and salicylates. Spectrochim Acta 17:486-502

47. Mirceski V, Gulaboski R, Lovric M, Bogeski I, Kappl R, Hoth M (2013) Square-wave voltammetry: a review on the recent progress. Electroanalysis 25:2411-2422

48. Mirceski V, Lovric KŠ, Lovric M (2007) Square-wave voltammetry. In: Scholz F (ed) Theory and application. Springer, Heidelberg

49. Nicholson RS, Olmstead ML (1972) In: Mattson SJ, Mark BH, Macdonald $\mathrm{CH}$ (eds) Electrochemistry: calculations simulation and instrumentation, vol 2. Marcel Dekker, New York

50. Mirceski V, Quentel F, L'Her M, Scholz F (2006) Studying the coupled electron-ion transfer reaction at a thin film-modified electrode by means of square-wave voltammetry. J Electroanal Chem 586:86-97 